Revista Iberoamericana, Vol. LXXIX, Núm. 242, Enero-Marzo 2013, 227-242

\title{
LA CONSTRUCCIÓN LOCAL DE LA MEMORIA: FOTOGRAFÍAS DEL MUSEO COMUNITARIO KAQJAY DE PATZICÍA, GUATEMALA
}

\author{
POR \\ BeATRIz CoRTEZ \\ California State University, Northridge
}

La tradición de los oprimidos nos enseña que el "estado de excepción” en que vivimos es la regla. Debemos llegar a un concepto de historia que corresponda a este hecho. Tendremos entonces ante nosotros, como nuestra tarea, la producción del estado de excepción efectivo [...]; con lo cual mejorará nuestraposiciónen la lucha contrael fascismo. Walter Benjamin

Ningún sacrificio es demasiado grande para nuestra democracia, y menos que nunca el sacrificio temporal de la democracia misma.

Clinton Rossiter

En julio de 2010 visité por primera vez el sitio arqueológico Kaqjay junto con colegas y estudiantes de mi universidad. Llegamos allí por invitación de los integrantes del colectivo del Museo Comunitario Kaqjay de Patzicía, pueblo kaqchikel localizado en el altiplano guatemalteco. Edgar Esquit, quien es historiador y antropólogo, llevaba entre sus manos un mapa del sitio arqueológico que había sido publicado por William Swezey como parte de "El primer informe de Cakhay" en 1998. En el paisaje se aprecian a simple vista varios de los montículos formados por las estructuras que están bajo tierra. Pero el diagrama nos ayudaba a imaginar este sitio arqueológico que cuenta con "dos plazas y una cancha de juego de pelota” (Swezey 7). Como caminamos desde la Carretera Panamericana, tuvimos la oportunidad de detenernos un momento al inicio del camino,

1 Es probable que esta forma de deletrear el término kaqchikel "kaqjay” provenga de la traducción al español de Adrián Recinos del Memorial de Sololá 118. 
frente a la Peluquería California, a tomarnos un retrato todos juntos. Más adelante el camino empinado nos quitó el aliento, no solamente por la dificultad de subir las colinas, sino también por la belleza de aquellos campos de flores y de distintos verdes marcados principalmente por los sembrados de repollo y de coliflor. Fue imposible visitar este lugar tan impresionante sin pensar que en aquellos paisajes hermosos había ocurrido la masacre de kaqchikeles en octubre de 1944 mientras la gente huía hacia el cerro imponente de San Andrés Itzapa o se escondía entre los zurcos. Recordé también que en aquellos caminos habían sido asesinados los hermanos Sisimit, ante cuya fotografía he reflexionado tantas veces en el Museo Kaqjay. Pero en esta oportunidad pensaba sobre todo que en aquellos parajes vivieron los kaqchikeles antiguos, quienes, según argumenta Adrián Recinos, tomaron su nombre del Caka Che’o árbol rojo (Crónicas 156). También los nombres de nuestros compañeros de viaje y guías de esta mañana, Brenda Loch y Víctor Hugo Ajquejay, me recuerdan la historia del surgimiento del pueblo kaqchikel en el Memorial de Sololá, pues esta nueva generación de mayas contemporáneos tiene los nombres de Loch y Xet de la familia de los Ahquehayi, antepasados de los kaqchikeles que en el Memorial de Sololá "dieron el ser [...] a la gente chakchiquel” (70).

Nuestra caminata desembocó en casa de don Julián Sirín, y entendimos entonces que encontrar uno de estos tesoros para alguien que aprecia lo que significa el legado cultural de los antepasados mayas es también una enorme responsabilidad. Mientras observábamos cómo en aquella casa se hacían portones de hierro tallado para vender, don Julián nos contaba que gran parte de sus ingresos son destinados para proteger el altar de Kaqjay que se encuentra en su casa. "Llegaron los arqueólogos para llevársela, pero la piedra no se quiso ir de aquí”, nos explicó. Quizá por ello don Julián ha tomado las responsabilidades no solamente de construir paredes de ladrillo y cemento que protejan al Altar 1 de Kaqjay, sino también de servir como guía espiritual, recibiendo numerosas visitas y explicando pacientemente una y otra vez la importancia del altar, participando en las ceremonias que cada visitante ha preparado, y mostrando con orgullo una nota amarillenta de un periódico local que cuenta la historia de cómo don Julián encontró este altar cuando excavaba en el patio de su casa por motivos de construcción.

De acuerdo con Benítez, este altar, conocido también como Altar 1, "se encuentra perfectamente alineado con el norte magnético, lo que demuestra el significado profundo que tuvo para el pueblo que dispuso de su locación”. Se trata de un altar del período clásico tardío, de un sitio que fue abandonado alrededor del año novecientos y luego ocupado nuevamente en el período posclásico(Benítez). El Memorial de Sololá menciona un intento por parte de los señores de Sololá por conquistarlo, intento que falló debido a un incendio (70-71). Más adelante el mismo texto indica cómo fue conquistado en el período posclásico: "El rey Lahuh Noh llevó sus armas a Cakhay. El día 8 Ganel [20 de enero de 1517] fue ocupada la fortaleza. Los jefes hicieron allí una demostración de fuerza verdaderamente grande. Llegaron todas las siete tribus, Hunyg y Lahuh Noh la hicieron” (118-19).

$$
\begin{aligned}
& \text { Revista Iberoamericana, Vol. LXXIX, Núm. 242, } \\
& \text { ISnero-Marzo 2013, 227-242 }
\end{aligned}
$$


El altar tiene cuatro lados que marcan las cuatro direcciones y tiene tallados con representaciones religiosas y cartuchos que marcan el tiempo. Una imagen aparenta ser un cocodrilo con dos cabezas, pero de acuerdo con Benítez ha sido interpretada como “[...] un zoomorfo cuya cabeza es la de un buitre y el cuerpo de un saurio probablemente caimán, con una cola que se enrolla al final. Cerca del enorme ojo muestra unas hendiduras curvadas como arrugas propias de los zopilotes”. Es un altar impresionante. También lo acompaña una piedra grande, aunque de menor tamaño que el altar, que representa a una serpiente de cuya boca sale una representación de un ser humano o de una deidad.

Como lo explica Benítez, hoy día este templo está localizado en un sitio que "conocen como aldea Los Cerritos Asunción, siendo jurisdicción del municipio de Patzicía, departamento de Chimaltenango”. A corta distancia se encuentra Patzicía; Kaqjay es su centro ceremonial más cercano. De acuerdo con Judith Maxwell y Robert Hill, traductores al inglés del Memorial de Sololá: Los anales de los Cakchiqueles y los Títulos de Xpantzay, Kaqjay se traduce literalmente como la casa roja (242), la cual, a su vez, representa en la narrativa del Popol Vuh y en la tradición oral a la casa de la cultura. Sin embargo, otras acepciones que ellos también mencionan se refieren precisamente a la colina llamada Kaqjay, la cual es uno de los sitios guardianes de Tecpán hoy en día (242), mientras que citan a Fuentes y Guzmán indicando que “Kaqjay [...] es una pequeña colina que domina a la ciudad” (242, mi traducción). En su nota explicatoria sobre la traducción que hacen del término kaqjay, Maxwell y Hill explican que "Kaqjay es también utilizado hoy día entre revitalizadores para significar 'museo' o 'lugar donde se resguardan las reliquias'” (242). En la traducción al inglés de Dennis Tedlock aparece una nota aclaratoria donde se indica que "la casa roja" representa "la gran pirámide” (Popol Vuh 302). Como lo explica Tedlock, en Kaqchikel “jay” significa “casa”, [...] (Popol Vuh 302) y "kaq" significa "hecho a mano" o "rojo”, concluyendo que "no es sorprendente que el término pirámide fuera (literalmente) 'casa roja', ya que las pirámides (y los templos que estaban localizados sobre ellas) fueran pintados de rojo, al menos durante el período clásico” (Popol Vuh 302, mi traducción).

Pero el Museo Comunitario Kaqjay también lleva en su nombre un término con una larga tradición occidental: museo. Se dice que el primer museo fue construido en un salón al lado de la Biblioteca de Alejandría. Otros sostienen que los primeros museos fueron los templos donde se guardaban los objetos de culto que en sesiones solemnes se exhibían a los fieles. O, que el museo representaba algo aún más lejano y misterioso: un lugar donde se guardaba lo que nunca se podía ver, aquello que de alguna manera era considerado sagrado (Vegas, sec. VI, s.p.). Como lo explica Federico Vegas, desde esta perspectiva occidental, el museo "es un lugar consagrado a las musas, todas hijas de Zeús y Menmosine, la diosa de la memoria” (Vegas, sec. III, s.p.). El nombre del Museo Comunitario Kaqjay representa, por tanto, la labor que lleva a cabo este colectivo kaqchikel, no solamente porque no se trata de un museo institucional sino de un museo comunitario concebido a partir de la acepción indígena de Kaqjay, sino también porque

\footnotetext{
Revista Iberoamericana, Vol. LXXIX, Núm. 242,
ISSN 0034-9631 (Impreso)
} 
es un nombre que define de manera precisa la labor del colectivo del Museo Comunitario Kaqjay y de este espacio: es un lugar donde se preserva la memoria antigua y la memoria reciente de los kaqchikeles de este lugar. ${ }^{2}$

El concepto del estado de excepción define un momento de emergencia a partir del cual se suspende la ley con el propósito de preservar el estado de derecho que sostiene ese mismo sistema legal. En las palabras de Giorgio Agamben, "el estado de excepción se presenta como la forma legal de lo que no puede tener forma legal” (Estado 10). Hay algunas variantes: a veces, la potestad de declarar el estado de excepción le corresponde al príncipe, otras, al líder del estado, otras más, a la asamblea constituyente. Cualquiera sea el caso, el estado de excepción suspende las garantías constitucionales, la ley y el derecho, y justifica esa suspensión, ya sea argumentando su necesidad o enfatizando el propósito de preservarlos. Como lo indica Agamben, "la teoría del estado de excepción se convierte entonces en una condición preliminar para definir la relación que liga al [ser] viviente con el derecho y, al mismo tiempo, le abandona a él” (Estado 10).

Al leer el estudio de Giorgio Agamben sobre el estado de excepción, sobre todo en lo que respecta a la genealogía del concepto, uno de los aspectos que saltan a la mente es que la genealogía del sistema legal que el autor examina proviene del así llamado "viejo mundo" y que las aplicaciones contemporáneas del concepto no toman en consideración el contexto particular ni las condiciones específicas de los países del continente americano, sobre todo en cuanto a lo que representa en este contexto la presencia indígena. De hecho, Agamben reproduce una de las metanarrativas de la modernidad en que Europa Occidental se coloca al centro del pensamiento moderno al ligar el concepto del estado de excepción europeo a la historia de Roma y de Grecia. Sin embargo, como lo ha demostrado Enrique Dussel, dicha genealogía de Europa es una "invención ideológica [...] que 'rapta' a la cultura griega como exclusivamente 'europea' y 'occidental'” (44). En este sentido, el estudio de Agamben sobre el estado de excepción está incrustado en la tradición moderna de Occidente. Por consiguiente, es un reto aplicar el concepto al contexto particular y a las condiciones específicas de la región latinoamericana. Por ello, llaman la atención dos casos particulares donde sus propuestas críticas desbordan el espacio delimitado por la modernidad de Occidente. El primero es su mención de los argumentos de Walter Benjamin respecto a la violencia y

2 Quiero agradecer a Jorge Brioso por sugerirme explorar el tema de las musas antiguas, particularmente Mnemosine. También agradezco a Yansi Pérez, Silvia L. López, Ricardo Roque Baldovinos, Douglas Carranza y Edgar Esquit por su lectura y contribuciones a este texto, lo que no les hace responsables de sus faltas.

Revista Iberoamericana, Vol. LXXIX, Núm. 242,
ISnero-Marzo 2013, 227-242 
sus posibilidades de existir fuera del espacio de la ley moderna, una violencia que, de acuerdo con Benjamin, "ni funda ni conserva el derecho, sino que lo suprime" (citado por Agamben, Estado 81). La obra de Benjamin, particularmente en sus últimos años, al enfrentarse al surgimiento del nazismo, presenta la posibilidad de concebir que el espacio de la ley moderna no lo abarca todo y de construir una crítica a la razón moderna y a la construcción moderna de la historia, del concepto de la violencia, y del concepto mismo de estado de excepción. El segundo es su mención a la obra del filósofo Baruch de Espinoza, cuya producción crítica es previa a la solidificación de la modernidad y cuyas propuestas sobre el derecho presentan alternativas a la razón moderna. Sin embargo, a pesar de que el resto de los textos citados por Agamben construyen una genealogía ajena al contexto centroamericano que me interesa estudiar, el concepto mismo de "estado de excepción" que propone y la tesis VIII sobre el concepto de la historia de Benjamin que he citado en el epígrafe a este ensayo nos proporcionan un aparato crítico desde el que es posible examinar la construcción de un sistema legal en el contexto centroamericano que, derivándose de la realidad europea, se aplicaba desde sus inicios únicamente a un segmento reducido de la población. Comparable con la definición del totalitarismo moderno que presenta Agamben, la imposición de la modernidad para el contexto centroamericano ante la marcada presencia indígena "puede ser definid[a] [...] como la instauración, por medio del estado de excepción, de una guerra civil legal, que permite la eliminación física no sólo de los adversarios políticos, sino de categorías enteras de ciudadanos que por cualquier razón no sean integrables en el sistema político" (Estado 11). Es decir, el estado de excepción ha sido en efecto la norma para la población indígena en el espacio de las naciones modernas de Centroamérica. Las palabras de Rossiter: "Ningún sacrificio es demasiado grande para nuestra democracia, y menos que nunca el sacrificio temporal de la democracia misma" (citado por Agamben, Estado 20) pueden aplicarse al contexo guatemalteco para referirse a un sacrificio impuesto sobre la población indígena en nombre de la modernidad, la cual incluye, por supuesto, el sistema legal que constituye el estado de derecho actual.

Para los propósitos de este ensayo, quisiera examinar de manera general algunas de las ideas que circularon a lo largo del proceso de transformación de un sistema colonial en la nación moderna para el caso particular de Guatemala. Mi propuesta es que el estado de derecho que hoy tratamos de salvaguardar para construir un sistema democrático en el actual período de la posguerra guatemalteca es un estado de derecho melancólico porque oculta o impide reconocer que está fundamentado en la eliminación del indígena del espacio donde el estado de derecho es aplicable, es decir, en su relegación a un permanente estado de excepción. Por supuesto, este estado de excepción permanente no significa que el indígena se conciba a sí mismo como víctima. Por el contrario, es precisamente su discurso de resistencia y de empoderamiento ante la gran narrativa de la nación que se lleva a cabo por medio de iniciativas locales lo que me interesa examinar

\footnotetext{
\begin{tabular}{l} 
Revista Iberoamericana, Vol. LXXIX, Núm. 242, Enero-Marzo 2013, $227-242$ \\
\hline ISSN 0034-9631 (Impreso)
\end{tabular}
} 
en este ensayo, tomando como ejemplo de ello la labor del Museo Comunitario Kaqjay de Patzicía en Guatemala.

II

El estado de derecho correspondiente al estado guatemalteco surgió paulatinamente a través de un proceso que dio inicio con la independencia y que culminó con el establecimiento del estado moderno de Guatemala. Sin embargo, la cuestión indígena ante el derecho fue un tema recurrente en la época colonial que ha quedado plasmado en los registros de debates como el que tuvo lugar en Valladolid, España, en 1550-1551 entre Bartolomé de las Casas y Juan Ginés de Sepúlveda. Es de notar que ninguno de los dos defendía el derecho de las poblaciones indígenas de preservar su cultura y su forma de ver el mundo, éste era más bien su punto en común. Su debate giraba en torno al derecho que tenía el gobierno colonial a recurrir a la violencia: las Casas argumentaba en contra de la violenta colonización de la población indígena, mientras que Sepúlveda, siguiendo las ideas aristotélicas sobre la superioridad de los pueblos, argumentaba por la violenta colonización de la población indígena como un derecho natural de los colonizadores europeos. Otro método por medio del cual se argumentaba culturalmente la diferenciación del trato del indígena en la sociedad colonial fue la implementación de una jerarquía de castas que colocaba al indígena en una posición de inferioridad respecto a su contraparte europea. No es sino hasta el período independentista cuando se establece un discurso de igualdad a la luz del surgimiento del estado de derecho moderno en un momento en que se ha eliminado el sistema de castas y reconocido teóricamente la igualdad del sujeto indígena. Entonces, el estado moderno en ciernes concibe la necesidad, informada por el racismo legado del período colonial, de excluir al sujeto indígena de forma permanente de la igualdad que le correspondía disfrutar ante la ley del estado moderno.

Este estado de excepción permanente al que se somete a la población indígena se construye a partir de la producción intelectual de quienes se reconocían a sí mismos como sujetos de la nación: los criollos y los ladinos. Ya en otro ensayo titulado "Racismo, intelectualidad, y la crisis de la modernidad en Centroamérica” he examinado algunas expresiones racistas que van entretejiendo la legalidad de la exclusión indígena en Guatemala. Entre ellas podemos mencionar la constitución de espacios académicos como la Sociedad de Geografía e Historia o la elaboración de leyes migratorias que buscaban la eliminación eugenésica de la población indígena por medio de su mezcla con la población europea con una historia colonial en Guatemala o de reciente importación. ${ }^{3}$

3 Ver por ejemplo el decreto 792, aprobado por la Asamblea Nacional Legislativa de la República de Guatemala el 7 de mayo de 1909 o el Decreto 1981, aprobado por el Presidente Jorge Ubico el 25 de enero de 1936.

$\begin{array}{llllll}\text { Revista Iberoamericana, Vol. LXXIX, Núm. 242, } & \text { Enero-Marzo 2013, 227-242 } \\ \text { ISSN 0034-9631 (Impreso) }\end{array}$ 
En la práctica puede documentarse por medio de numerosos ejemplos, entre los que sobresale la eliminación de las tierras comunales o ejidos en las zonas que habían sido destinadas para la producción del café y la implementación de leyes de vagancia que garantizaban mano de obra barata o gratuita a la nueva comunidad cafetalera. Otro ejemplo de épocas más recientes ha sido la definición de comunidades indígenas enteras como enemigos del estado y la subsecuente orden de su eliminación por parte del estado guatemalteco. Entre las comunidades que fueron blanco de estas políticas genocidas puede mencionarse la población del triángulo Ixil, es decir, de las aldeas de Nebaj, San Juan Cotzal y Chajul durante el recién concluido conflicto armado. En la vida cotidiana a lo largo de la historia guatemalteca abundan ejemplos en que la población indígena ha sido o es tratada como ciudadanos de segunda categoría.

III

Por supuesto, la gran narrativa de la nación moderna guatemalteca no corresponde a la experiencia cotidiana en el espacio nacional y, por consiguiente, hay múltiples espacios de resistencia que surgen, sobre todo a nivel local, dentro del mismo espacio de la nación. Por ello me interesa explorar las posibilidades para la labor de un proceso de duelo y de reelaboración de la identidad, así como de la elaboración de la memoria a nivel local, que surgen desde el interior de las comunidades indígenas, con interlocutores mayoritariamente de la comunidad misma. Es con este propósito que llevo a cabo esta reflexión sobre el trabajo de recuperación de la memoria histórica y de construcción/ reelaboración de la identidad local que llevan a cabo los integrantes del colectivo indígena del Museo Comunitario Kaqjay de la población kaqchikel de Patzicía en el altiplano guatemalteco.

El Museo Comunitario Kaqjay de Patzicía fue establecido en 2006, aunque fue inaugurado formalmente en el local que ocupa en la actualidad en octubre de 2008. Su labor ha sido muy diversa y ha generado programas educativos, exposiciones, y también un proyecto para la recuperación del archivo municipal. En este ensayo exploro de manera particular la exposición del Museo Comunitario Kaqjay en la Universidad de Costa Rica, en julio de 2009, durante el II Congreso Centroamericano de Estudios Culturales. La muestra contaba con dos exposiciones. Una exposición con formato más pequeño y marcos blancos presentaba una colección de las víctimas del conflicto armado en la municipalidad de Patzicía durante los años ochenta. La otra, con marcos negros y fotografías de tamaños un poco más amplios y formatos diversos, incluía una colección de imágenes históricas de la Municipalidad de Patzicía entre 1940 y 1980. Es ante estas fotografías que reflexiono sobre la construcción local de la memoria histórica y también sobre la construcción local de la identidad.

Ambas colecciones presentan fotografías que fueron tomadas en otro contexto, con propósitos distintos del de ser incluída la fotografía en esta exposición. La colección

Revista Iberoamericana, Vol. LXXIX, Núm. 242,
ISSN 0034-9631 (Impreso) 
de imágenes de las víctimas del conflicto armado, por lo tanto, incluye fotografías que documentan la ausencia de las víctimas, pero que también buscan generar condiciones para reconstruir una dimensión humana de ellas. Me interesa ante estas fotografías considerar el silencio de los muertos. Cuando no fue posible para las víctimas sobrevivir, estas imágenes son de hecho lo que sobrevive a los muertos, lo que queda de ellos. Por otro lado, las imágenes históricas de Patzicía muestran momentos en la vida cotidiana de familias indígenas del pueblo, pero también momentos importantes de sus vidas como bodas, la fiesta del pueblo, la elección de la reina indígena, la procesión en honor a Santiago, campeonatos deportivos, el baile de moros y cristianos, y otros momentos cruciales en su historia del pueblo, como, por ejemplo, el terremoto de 1976.

Respecto a la primera exposición, una de las preguntas que surge ante las imágenes es, ¿de qué manera contribuyen a humanizar a las víctimas, a restaurar su humanidad? Esta colección fue elaborada con la colaboración de los familiares de las víctimas, quienes, cuando había sido posible, habían proporcionado a Kaqjay una fotografía de estas personas, y una breve nota indicando las condiciones bajo las que fueron asesinados. En la colección hay varias fotografías inexistentes. En su lugar figura una silueta negra que indica que los familiares de las víctimas o no poseían ninguna fotografía de estas personas o se vieron obligados a destruir todas las imágenes que tenían de sus familiares. Guardar esas imágenes pudo haber representado una sentencia de muerte para ellos. La ausencia de estas imágenes es impactante porque deja testimonio de la existencia de un ser humano a la vez que marca una doble ausencia. Entonces, su silencio es amplificado por la ausencia de su imagen. No podemos escuchar sus palabras, es decir, su testimonio, y tampoco podemos ver su rostro.

Esta exposición no es la primera oportunidad en que he visto estas fotografías. Hace varios años que estoy en contacto con el colectivo del Museo Comunitario Kaqjay de Patzicía y que colaboro con ellos. Entre otras actividades, organizamos juntos una exposición de otra colección de sus fotografías históricas de la Municipalidad de Patzicía en la Universidad Estatal de California, Northridge, en abril de 2008. Por eso, hace también mucho tiempo que reflexiono ante estas fotografías, que son las imágenes de sus muertos, de las víctimas del recién concluido conflicto armado en la municipalidad de Patzicía. A pesar de nuestra colaboración nos separa una distancia cultural y física. Hemos pasado algún tiempo juntos, pero no conozco con gran profundidad a cada uno de ellos ni a sus familias. Sin embargo, les considero amigos. El título de cada una de las fotos pesa sobre mí porque define los lazos de parentesco entre los miembros de la comunidad de Patzicía hoy día y los que aparecen retratados en estas imágenes: el hijo de Juana, la hija de Juana, el padre de Edgar. Estas víctimas del conflicto armado han dejado de ser víctimas anónimas. Han dejado también de ser simplemente números. Por medio de sus historias y de la labor de memoria de sus familiares y de su comunidad, estas víctimas recuperan una dimensión de su humanidad.

$\begin{array}{llllll}\text { ISSN 2154-4794 (Electrónico) } & \text { Revista Iberoamericana, Vol. LXXIX, Núm. 242, Enero-Marzo 2013, }\end{array}$ 
La pregunta ante estas fotografías no debe limitarse únicamente al contexto en el que surgieron, sino también al contexto en el que las vemos. Es decir, en el contexto ante el que nos encontramos como espectadores estas fotografías también dejan testimonio de que para los familiares de las víctimas, para los miembros de su comunidad y para los integrantes del colectivo del Museo Comunitario Kaqjay de Patzicía estas personas contaban como seres humanos y su ausencia es causa de duelo personal, colectivo y comunitario. Por eso, ante estas fotografías, me parece importante hacer las mismas preguntas que la filósofa Judith Butler hace en otro contexto: “¿Quién cuenta como un ser humano? ¿Cuáles vidas cuentan como vidas? y, finalmente, ¿Qué es lo que conforma una vida cuya pérdida amerite el duelo?” (20, énfasis en el original). ${ }^{4}$ Pero referirnos a la pregunta que surge al leer este ensayo de Butler sobre la precariedad y vulnerabilidad de la vida humana también nos lleva a otra pregunta que debemos hacernos ante la realidad en la que vivimos donde hay vidas que cuentan como vidas humanas y otras que no, cuyas pérdidas no se lamentan públicamente como pérdidas y por quienes no se lleva a cabo una labor de duelo: ¿Para quién cuentan estas vidas?

Para la gente de Patzicía las víctimas del conflicto armado de su comunidad cuentan como seres humanos, como víctimas, como vidas humanas cuya pérdida debe lamentarse, cuyo asesinato amerita un duelo personal pero también un duelo colectivo. Sin embargo, basta leer sus historias para darnos cuenta de que para el estado guatemalteco que los asesinó en los años de la guerra ellos no contaban como seres humanos y sus vidas cegadas por la violencia no eran pérdidas que ameritaran el duelo.

Es así que esta colección de fotografías no recupera únicamente sus historias personales, no repara únicamente su calidad humana ante el estado que los asesinó, sino que también deja testimonio de los métodos por medio de los cuales el estado da forma a la modernidad a partir de la construcción del otro, de la nación moderna como un no-ciudadano y como un ser que no cuenta. Como señala Giorgio Agamben al hablar sobre la representación del estado moderno de "la vida que no merece vivir", "la estructura biopolítica fundamental de la modernindad [es] la decisión sobre el valor (o sobre el disvalor) de la vida como tal” (Homo Sacer 173). Este no-ciudadano, a pesar de ser analizado, clasificado y organizado siguiendo métodos taxonómicos, y a pesar de ser el blanco de políticas del bio-poder, es un ser que para los propósitos del estado moderno no ha existido nunca. Desde la perspectiva del estado, "no puede ser lamentada su pérdida porque desde siempre han estado perdidas o, más bien, nunca 'fueron', y deben asesinarse ya que parecen insistir en continuar viviendo, con necedad, en este estado de muerte (Butler 33, mi traducción).

Por consiguiente, para el estado moderno, "algunas vidas serán protegidas altamente, $[. .$.$] otras vidas no encontrarán tal inmediato y furioso apoyo y ni siquiera$

4 Todas las traducciones son mías.

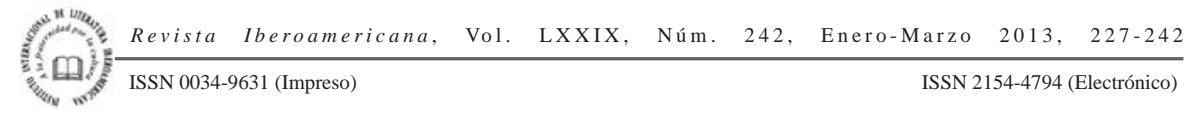


calificarán como vidas cuya pérdida merezca ser lamentada” (Butler 32, mi traducción). En ese contexto, esta exhibición nos invita a comprender que la humanidad implica vulnerabilidad, pues “el cuerpo implica mortalidad, vulnerabilidad, agencia: la piel y la carne nos exponen a la mirada de los otros, pero también a su tacto, y a la violencia, y los cuerpos nos ponen en riesgo de convertirnos en agencia y en instrumento de todos ellos también" (Butler 26, mi traducción). Por otro lado, al resaltar la humanidad de las víctimas también se deja en evidencia que el luto no es sólo íntimo, interno, privado, sino también comunitario y político. Como lo indica Butler,

Muchas personas piensan que el duelo es privatizador, que nos regresa a una situación solitaria y que es, en ese sentido, despolitizador. Pero yo pienso que proporciona un sentido de comunidad política de un orden complejo, y que logra esto antes que nada resaltando los lazos que tienen implicaciones para la teorización de la dependencia fundamental y de la responsabilidad ética. (22, mi traducción)

Al respecto de esta dimensión política del duelo colectivo, es importante también considerar la posibilidad de que "reinstaure nuestro sentido de vulnerabilidad humana, nuestra responsabilidad colectiva por las vidas físicas de los demás” (30, mi traducción).

Me parece aquí importante detenerme un momento para examinar el pronombre "nosotros" que surge ante esta experiencia. Pues nosotros sólo puede funcionar en este contexto ante el concepto vago de humanidad. Como indica Susan Sontag frente a una colección de fotografías con características comparables a las que aquí nos ocupan, "ningún 'nosotros' debe tomarse por sentado cuando el sujeto mira al dolor de otras personas” (7, mi traducción), sobre todo cuando, como en este caso, se trata de indígenas ante un espectador no-indígena.

Pero ante la muerte de los otros sí surge la conciencia de la vulnerabilidad de la vida, de la precariedad de la humanidad. Es decir, surge la pregunta sobre si la condición humana, entendida de forma universalista o eurocéntrica, es instrínseca a las personas o si depende completamente del valor que a cada una de estas vidas le asigne el poder (el bio-poder) del estado moderno. Entonces, la pregunta que surge cuestiona también cuál ha sido nuestra propia complicidad, si no con ese estado moderno militarizado que asesinó a estas víctimas, sí con el concepto de modernidad que este estado promueve, sobre el que edifica su poder, con el que justifica la clasificación de las personas como vidas que ameritan vivirse y como vidas que no valen nada. Y, en un país como Guatemala, con una población tan diversa; ¿en qué sentido hemos sido (somos) cómplices de la imposición de la modernidad? Y yo, que no soy indígena, ¿miro estas fotos también como un indicio de los métodos por medio de los cuales se ha mantenido mi propio privilegio? Por eso recuperar la humanidad de las víctimas del conflicto armado para esta comunidad kaqchikel, y para quien mira estas fotos, no solamente es un proceso colectivo de luto compartido, es también una cuestión ética.

\footnotetext{
Revista Iberoamericana, Vol. LXXIX, Núm. 242, Enero-Marzo 2013, $227-242$
ISSN 2154-4794 (Electrónico)
} 
Aunque Butler escribe sobre el contexto de la guerra de Estados Unidos en Irak, sus ideas aplican al contexto de la posguerra guatemalteca respecto a los esfuerzos por idear la construcción de la memoria. Para muchas de las víctimas de este conflicto no hay obituarios y, como Butler observa, desde la perspectiva del estado " [...] no puede haberlos. Si hubiera un obituario, tendría que haber habido una vida, una vida notable, una vida digna de valorar y preservar, una vida que calificara para reconocimiento" (34, mi traducción). Pues para Butler "el obituario [es] un acto constitutivo de la nación” (34, mi traducción). Pero, a pesar de los ninguneos en el espacio público nacional, aquí en esta exposición se recoge una suerte de obituarios para las víctimas, es decir, una narración de sus vidas y de las condiciones bajo las que fueron asesinadas estas personas. Si en la nación-estado no hay obituarios, en el espacio local se han recuperado.

Leo las historias de la víctima con atención. De esta forma me entero de la muerte gratuita de dos hermanos, ambos agricultores. Don Basilio Sisimit Pichiyá, quien, de acuerdo con el texto colocado junto a cada una de las fotografías en la exposición, "[...] fue baleado el 20 de octubre de 1993 por hombres desconocidos que perseguían a otra persona, entre la aldea la Canoa y el Chuluc. Cuando don Basilio quiso defender al perseguido, él fue ametrallado en aquel lugar” (Museo). Ese mismo día su hermano, don Antonio Sisimit Pichiyá, "fue acribillado a tiros por personas desconocidas”, indica el texto que "cuando vio a su hermano Basilio tirado en la calle, bajó de su caballo para ayudarlo, en ese momento fue asesinado por personas desconocidas".

Encuentro también la historia de Arnulfo, quien fue secuestrado y después desaparecido tan solo un día después de que su esposa, Gabina Martín, diera a luz. Gabina también fue secuestrada junto con su esposo y torturada por un período de un mes. Me pregunto qué habrá sido de su bebé recién nacido. En una historia paralela, Mariana Solomán Olcot también estaba embarazada cuando fue secuestrada. ¿Qué habrá sido de su bebé?

Entre las historias sobresale el hecho de que muchas de las víctimas del conflicto armado en Patzicía eran muy jóvenes, como Ceferino Curruchich Colaj, quien desapareció a la edad de diecisiete años; o Israel Choc Panteul, quien fue secuestrado a la edad de dieciocho años; o Rigoberto Loch Rosales, quien fue desaparecido a la edad de diecisiete años; o Santiago Alberto Túrcios, quien fue asesinado en una calle de Patzicía a la edad de veintiún años.

Otro aspecto que sobresale es la responsabilidad del ejército y de la policía en los asesinatos, torturas y secuestros de las víctimas del conflicto armado de la Municipalidad de Patzicía. El secuestro y tortura de Gabina Martín, así como la desaparición de su esposo Arnulfo en 1982, fue abiertamente perpetrado por miembros del ejército. Ceferino Curruchich Colaj desapareció en 1980, luego de ser capturado por la Policía Nacional. Esteban Ajuchán Choy fue capturado por miembros del ejército mientras caminaba en la Carretera Interamericana en 1982. Israel Choc Panteul fue secuestrado por comisionados

\footnotetext{
\begin{tabular}{l} 
Revista Iberoamericana, Vol. LXXIX, Núm. 242, Enero-Marzo 2013, $227-242$ \\
\hline ISSN 0034-9631 (Impreso)
\end{tabular}
} 
militares y después desaparecido por policías judiciales en 1981. Don Josué Perobal Ajuchán fue una de las víctimas de una masacre perpetrada por miembros del ejército en la Comunidad La Esperanza, el 18 de mayo de 1989; fue asesinado a quemarropa junto con su tío y su cuñado, don Mauro Gómez Miculax, y otros dos miembros de su comunidad. La población tampoco estaba a salvo al interior de sus propias casas, como lo demuestra la captura de Felipe Sanic Chamba, quien "fue secuestrado por el ejército a eso de las cinco de la mañana en su casa de habitación, ubicada en el tercer cantón de la aldea El Camán, el día 25 de octubre de 1982” (Museo). El 3 de noviembre de 1982 el predicador de la Iglesia Católica de esa misma aldea fue secuestrado y desaparecido por miembros del ejército mientras se encontraba en su casa de habitación. Tránsito Gabriel Pichiyá "fue ejecutado por miembros del ejército el 19 de junio de 1982 a las siete de la noche en el interior de su casa [...]. El crimen fue cometido delante de su padre, cuñado y dos de sus hijos” (Museo). De igual forma Mariana Solomán Olcot fue capturada por el ejército mientras se encontraba en su casa en 1984.

Las familias de las víctimas los buscaron: en el caso de Ceferino Curruchich Colaj, el texto indica que "la madre realizó diligencias para que lo dejaran en libertad pero nunca regresó” (Museo). En el caso de Israel Choc Panteul, se señala que "los padres hicieron todas las diligencias para que lo dejaran en libertad pero sus captores no lo permitieron”. En el caso de Rigoberto Loch Rosales, el texto indica que "sus padres y otras personas lo buscaron en diferentes lugares, en cárceles, hospitales y en algunos destacamentos o bases militares, pero no lo localizaron”. Es muy posible que algunas de estas familias todavía les sigan buscando, pues varias de las historias dejan en evidencia la imposibilidad que tuvieron para poder dar conclusión a la historia de las vidas de sus seres queridos. El texto indica que en el caso de Agustín Guóz "su familia esperó su regreso pero nunca lo volvieron a ver”. En el caso de Santos Solomán Olcot se indica que "nunca más se supo de su paradero".

Al mirar la colección de imágenes históricas de Patzicía después de ver la exposición sobre las víctimas del conflicto armado las fotografías antiguas adquieren un nuevo significado. Mientras veo la Calle Real pienso también que éste fue el sitio donde fue asesinado don Arturo Esquit Xicay, y al ver a los miembros de Santiaguito, equipo de fútbol, me pregunto si esa imagen incluirá a don Otto Fernando Martín Yancoba. Las muertes, las pérdidas, la memoria, son parte también de la vida en Patzicía.

\section{IV}

En otros ensayos he explorado el carácter melancólico de la identidad nacional y la forma en que éste se reproduce en la literatura centroamericana. La melancolía que se expresa por medio de la producción literaria no solamente falla en reconocer las

\footnotetext{
Revista Iberoamericana, Vol. LXXIX, Núm. 242, Enero-Marzo 2013, $227-242$
ISSN 2154-4794 (Electrónico)
} 
pérdidas humanas que han tenido lugar entre nosotros durante los recientes conflictos armados en la región, sino también la forma en que la nación se fundó en base a la exclusión del otro del sujeto nacional, es decir, las poblaciones indígenas y negras de Centroamérica. ${ }^{5}$ Más allá del campo literario, la producción cultural en Centroamérica, en general, y en Guatemala, en particular, se caracteriza por su incapacidad para llevar a cabo un proceso de duelo que le permitiera procesar en la posguerra la experiencia de haber vivido en una guerra y así reflexionar sobre la condición humana. Por otra parte, he explorado también la forma en que la literatura opera como una herramienta de la nación moderna que busca reproducir el mandato de la subjetividad nacional en base al sujeto mestizo/ladino y en exclusión de la diversidad cultural y étnica de la región. ${ }^{6}$ Esto se lleva a cabo, por ejemplo, dando un lugar primordial, prácticamente de exclusividad, a la producción literaria en español y tomando como punto de referencia para la valoración de la producción artística a los parámetros culturales importados de Europa.

De hecho, he argumentado que este proceso de duelo no podrá llevarse a cabo antes de lidiar con un duelo mucho más antiguo, mucho más pendiente, el duelo ante el otro de la nación que existe en la vida cotidiana y en la realidad, pero que en el espacio simbólico de la nación existe únicamente en su concidión melancólica, sin ningún reconocimiento en el panorama cultural de la nación moderna. La identidad nacional de la nación moderna se construyó como un espacio homogéneo que celebraba la identidad mestiza/ ladina del nuevo sujeto nacional. Por consiguiente, el lugar del otro de la nación estaba únicamente en el pasado. El sujeto indígena, por lo tanto, disfruta de reconocimiento en el espacio de la nación moderna únicamente como parte del pasado antiguo (nuestras raíces) y como un sujeto que tuvo o que tiene que ser erradicado, si no literalmente, al menos simbólicamente, del espacio nacional. Esta condición de violencia ante el otro de la nación es una de las características fundamentales de una nación moderna con un sujeto cohesivo, homogéneo y rígido y una realidad demográfica que lo contradice.

Ante esta realidad, no es descabellado analizar la situación de las poblaciones indígenas de manera comparable con la de la figura del refugiado en las naciones primermundistas de la actualidad, con la considerable diferencia de que esta condición de refugiado que obliga al sujeto indígena a vivir bajo un permanente estado de excepción tiene lugar en su propia tierra, bajo la tutela de su propia patria. Así, podemos aplicar las propuestas de Benjamin respecto a que "el estado de excepción bajo el que vivimos es la regla” (citado por Agamben, Estado 86), como también la afirmación de Agamben sobre el refugiado que "en el sistema del estado-nación, los así llamados sagrados e inalienables derechos humanos se muestran sin protección alguna precisamente cuando ya no es posible concebirlos como derechos de los ciudadanos de un estado" (Means

5 Ver Cortez, “Mapas de melancolía”, 135-49.

6 Ver Cortez, “¿Dónde están los indígenas?”, 153-67.

Revista Iberoamericana, Vol. LXXIX, Núm. 242,
Enero-Marzo 2013, 227-242 
19-20; mi traducción), a la situación de la población maya ante el estado guatemalteco. En otras palabras, los derechos humanos que tanto son citados en el discurso político actual no parecen ser intrínsecos al ser humano, pues son puestos en práctica únicamente cuando una persona ha obtenido pleno reconocimiento como ciudadano por parte de un estado moderno. Sin este reconocimiento los derechos del ser humano no tienen lugar en el estado-nación. Como indica Agamben, "un estatuto estable para el [ser] humano en sí mismo es inconcebible para la ley del estado-nación” (Means 20; mi traducción). Es decir que "los derechos [...] le son atribuidos al ser humano solamente en el grado en que él o ella opere como la presuposición inmediatamente invisible [...] del ciudadano" (21; mi traducción).

Por consiguiente, la presencia del refugiado en el estado moderno demuestra que la ley no lo cubre todo y que existe vida fuera del espacio y la protección de la ley, y si la situación de la población indígena al interior del estado guatemalteco es comparable con la del refugiado en el estado moderno por su existencia fuera de la protección de la ley, entonces su existencia bajo un estado de excepción permanente deja testimonio de la crisis de la modernidad en Centroamérica. Pues citando a Agamben, "cuando sus derechos ya no son los derechos de un ciudadano, entonces es cuando los seres humanos están verdaderamente [...] condenados a morir” (Means 22; mi traducción). Expandiendo esta idea más allá del derecho al espacio de la historia cultural podemos argumentar que el sujeto indígena no solamente denota la crisis de la modernidad, sino también deja en evidencia la cualidad melancólica de la construcción de la modernidad en Centroamérica. Es decir, en un contexto como el guatemalteco, la construcción de la modernidad requiere la exclusión no reconocida de la mayoría de la población del espacio de la ley, de la escritura de la historia del estado moderno, de los procesos oficiales de construcción de la memoria nacional, y del espacio que abarca el estado de derecho.

V

En conclusión, las historias que documenta esta memoria fotográfica y textual de las víctimas del conflicto armado en Patzicía y su presencia en las fotografías históricas de la misma localidad dejan en evidencia la existencia de estas vidas vividas bajo permanente estado de excepción y cegadas en negación de su humanidad. Pero también dejan testimonio de las voces que surgen desde el espacio local para construir su memoria y restituir su humanidad. Y es ante esta ceremonia de luto por las víctimas del conflicto armado que surge la necesidad de escuchar las voces que desde el espacio local desarticulan la narrativa homogeneizante de la nación moderna para dejar por sentado la diversidad de perspectivas culturales, la humanidad que no es reconocida por el estado-nación y la vida que se vive fuera de la protección de la ley, fuera del estado de derecho, en un estado permanente de excepción.

ISSN 0034-9631 (Impreso) 
Es además una oportunidad para explorar nuevas interrogantes que surgen a partir de este planteamiento. Estas nuevas preguntas nos permitirán considerar si estamos siempre forzados a partir del estado-nación moderno para construir nuestras narrativas de la memoria, de la historia, de la ley, del derecho y de la democracia o si hay otras alternativas que nos permitan mirar más allá, en un espacio donde podamos desbordar los límites que nos ha impuesto la modernidad y que no reflejan la realidad cotidiana en el contexto centroamericano.

\section{BiBLIOGRAFÍA}

Agamben, Giorgio. Estado de excepción: Homo sacer II, 1. Antonio Gimeno Cuspinera, trad. Valencia: Pre-Textos, 2004.

Homo Sacer: El poder soberano y la nuda vida. Antonio Gimeno Cuspinera, trad. Valencia: Pre-Textos, 1998.

Means without End: Notes on Politics. Vincenzo Binetti y Cesare Casarino, trads. Minneapolis: U of Minnesota P, 2000.

Benítez, José E. “El altar 1 de Cakhay”. XVII Simposio de Investigaciones Arqueológicas en Guatemala. J. P. Laporte, B. Arroyo, H. Escobedo y H. Mejía, eds. Guatemala: Museo Nacional de Arqueología y Etnología, 2004. <http://asociaciontikal.com/ pdf/17.03\%20-\%20Benitez\%20-\%20en\%20PDF.pdf>. 13 abril 2011.

Benjamin, Walter. Discursos interrumpidos I: Filosofía del arte y de la historia. Jesús Aguirre, ed. y trad. Madrid: Taurus, 1971.

Butler, Judith. Precarious Life. The Powers of Mourning and Violence. Londres: Verso, 2006.

Carranza Mena, Douglas. Indigenous Communities and the Ethnography of Governmentality in El Salvador. Tesis doctoral. University of California, Santa Barbara, 2003.

Casas, Bartolomé de las. En defensa del indio. Sevilla: Editoriales Andaluzas Unidas, 1985.

Cortez, Beatriz. “¿Dónde están los indígenas? La identidad nacional y la crisis de la modernidad en La guerra mortal de los sentidos de Roberto Castillo”. Historia y ficción en la novela contemporánea en Centroamérica. Rolando Sierra, Werner Mackenbach y Magda Zavala, eds. Tegucigalpa: Editorial Zubari, 2008. 153-67.

"Mapas de la melancolía: la literatura como medio para la homogeneización del sujeto nacional”. Intersecciones y transgresiones. Tomo I de Hacia una historia de la literatura centroamericana. Werner Mackenbach, ed. Guatemala: F\&G Editores, 2008. 135-49.

"Racismo, intelectualidad, y la crisis de la modernidad en Centroamérica”. Tensiones de la modernidad: del modernismo al realismo. Tomo II de Hacia una

Revista Iberoamericana, Vol. LXXIX, Núm. 242, Enero-Marzo 2013, $227-242$
ISSN 2154-4794 (Electrónico) 
historia de la literatura centroamericana. Valeria Grinberg Pla y Ricardo Roque Baldovinos, eds. Guatemala: F\&G, 2009. 415-39.

Crónicas indígenas de Guatemala. Adrián Recinos, ed. Guatemala: Editorial Universitaria, 1957.

Dussel, Enrique. "Europa, modernidad y eurocentrismo". La colonialidad del saber: eurocentrismo y ciencias sociales. Perspectivas latinoamericanas. Edgardo Lander, ed. Buenos Aires: CLACSO, 2005. 41-53.

Ginés de Sepúlveda, Juan. Tratado sobre las causas justas de la guerra contra los indios. México: Fondo de Cultura Económica, 1941.

Ginés de Sepúlveda, Juan y Bartolomé de las Casas. Apología. Ángel Losada, ed. y trad. Madrid: Nacional, 1975.

Kaqchikel Chronicles: The Definitive Edition. Judith Maxwell y Robert M. Hill, trad. e intro. Austin: U of Texas P, 2006.

Memorial de Sololá. Anales de los cakchiqueles. Título de los señores de Totonicapán. Adrián Recinos, ed. México: Fondo de Cultura Económica, 2006.

Museo Comunitario Kaqjay de Patzicía. Exposición fotográfica. Universidad de Costa Rica. II Congreso Centroamericano de Estudios Culturales. Julio 2009.

Popol Vuh: The Definitive Edition of the Mayan Book of the Dawn of Life and the Glories of Gods and Kings. Dennis Tedlock, trad. 2a ed. Nueva York: Touchstone, 1996.

Rossiter, Clinton. Constitutional Dictatoriship: Crisis Government in the Modern Democracies. Princeton: Princeton UP, 1948.

Sontag, Susan. Regarding the Pain of Others. Nueva York: Ferrar, 2002.

Swezey, William R. "El primer informe de Cakhay”. Mesoamérica 35 (1998): 7-26.

Vegas, Federico. "Unas palabras a los museólogos”. Universidad Central de Venezuela. 10 oct. 2010. <http://prodavinci.com/2010/10/10/artes/unas-palabras-a-losmuseologos/>. 10 feb. 2011. 